\title{
Localized scleroderma, associated with Lyme disease
}

\section{Introduction}

Localized scleroderma (morphea) is a chronic disease with progressive long-term passing, characterized by a lesion of connective tissue with a predominance of fibro-sclerotic and vascular disorders in the skin. The etiology of localized scleroderma is not fully understood. According to the works of many authors, provocative factors may include injuries, ischemic tissue damage, radiation effects, stress, neuro-endocrine disorders, chemico-medicamentous agents, viral or bacterial infection. A suspected trigger of morphea can be tick-borne infection: Lyme disease. According to the Order of the Minister of Health of Ukraine N133 of 19.07.1995, Lyme borreliosis is officially classified as a group of especially dangerous infections. But, the registration of Lyme disease in Ukraine began in 2000 , and the incidence of this disease in the country is growing each year, with 58 cases reported in 2000, and 3946 cases in 2017. The Ternopil region, located in the western part of Ukraine, is an endemic area of Lyme disease. Habitats of the tick Ixodes ricinus were found in 57 settlements of the 15 districts in the vicinity of Ternopil. This infection can have an effect on the severity of the course of the disease. Localized scleroderma can have varying degrees of severity. There are several methods for assessing the severity of localized scleroderma: LoSDI (The Localized Scleroderma Damage Index), LoSSI (The Localized Scleroderma Skin Severity Index).

\section{Methods}

The present studies based on 40 patients, which conducted a questionnaire and laboratory examination. The age of tested persons ranged from 18-74years. The group of examined patients comprised 10 men and 30 women. Patients treated in Ternopil regional clinical dermatovenerologic dispensary. According to the presence of antibodies against Borrelia burgdorferi s.l, all patients were divided into two groups: the 1st group-19 patients with only localized scleroderma, the $2^{\text {nd }}-21$ patients with localized scleroderma, associated with Lyme disease. The diagnosis of localized scleroderma was established clinically according to the classification of ICD-10. ${ }^{1}$

Sera of all tested patients was examined for the presence of anti-Borrelia burgdorferi s.l. antibodies with the use of ELISA test, determining the level of specific $\operatorname{IgM}$ and $\operatorname{IgG}$ immunoglobulins (Euroimmun, Germany). The test was carried out according to producer's instructions. The Localized Scleroderma Skin Severity Index (LoSSI) is calculated by summing 4 domain scores: surface area score (SA), erythema (ER), skin thickness score (ST), new lesion/ lesion extension $(\mathrm{N} / \mathrm{E})$ in 18 coetaneous surface anatomic sites. The most severe or highest score of each domain (SA, ER, ST, and N/E) of lesions in a given anatomic site are summed to obtain the LoSSI (range 0-216). The results of the study were statistically analyzed using the Statistica v. 10 programmers. ${ }^{2}$

\section{Results}

Positive or doubtful result in at least one class of antibodies IgM/ IgG was observed in $21(52.5 \%)$ of respondents: IgM antibody-in $9(42.9 \%), \mathrm{IgG}-$ in $12(57.1 \%)$. The severity index in patients with
Volume 2 Issue 4 - 2018

\author{
Shkilna MI, Yavorska KB \\ Department of Infectious Diseases and Epidemiology, Ternopil \\ State Medical University, Ukraine
}

Correspondence: Shkilna Mariia, Department of Infectious Diseases and Epidemiology, Dermatology and Venereology, I. Horbachevsky Ternopil State Medical University, Ukraine, Tel +38097570 8266, Email nadiya20743@gmail.com

Received: March 21, 2018| Published: July 27, 2018

only localized scleroderma was 5.1 points on average, in patients with morphea, associated with Lyme disease-3.76, respectively. According to the results of the evaluation of each of the 4 domain scores of the severity index, the mean values of the "surface area score (SA)", "erythema (ER)" and" new lesion/lesion extension (N/E)" scores were not significantly different between patients in both groups. The score of density (ST) in patients of the $1^{\text {st }}$ group was 1.94 points, in patients of the 2 nd group -0.9 , respectively. ${ }^{3}$

\section{Conclusion}

The index of the severity of localized scleroderma associated with Lyme disease was lower than in respondents only with morphea, in particular due to the skin thickness. The presences of specific antibodies against Borrelia burgdorferi s.1 were detected in 52.5\% patients with morphea. This indicates an association between morphea and Borrelia burgdorferi sensu lato complex in patients from Ternopil region. Therefore the subject of our study requires further attention of the dermatologist not only from Ukraine, but from the whole world as well.

\section{Acknowledgements}

None.

\section{Conflict of interest}

Author declares that there is no conflict of interest.

\section{References}

1. Romanenko KV, Gritsay OD. About the role of Borrelia burgdorferi in the development of lokalized scleroderma. The questions of experimental and clinical medicine: a collection of articles. 2010;14(2):161-164.

2. Tokarska-Rodak M, Shkilna M, Plewik D. Serological research towards Lyme borreliosis in hunters and forestry workers in selected areas of Poland and Ukraine. Health Problems of Civilization. 2018;11(4):287-292.

3. Arkachaisri T, Vilaiyuk S, Li S, et al. The localized scleroderma skin severity index and physician global assessment of disease activity: a work in progress toward development of localized scleroderma outcome measures. J Rheumatol. 2009;36(12):2819-2829. 